\title{
CORRIGENDUM
}

\section{The prevalence of erectile dysfunction in men visiting outpatient clinics}

J Haczynski, Z Lew-Starowicz, B Darewicz, K Krajka, R Piotrowicz and B Ciesielska

International Journal of Impotence Research (2006) 18, 578. doi:10.1038/sj.ijir.3901455

Correction to: International Journal of Impotence Research (2006) 18, 359-363. doi:10.1038/

sj.ijir.3901435

Following the online publication of this article, the authors sent the revised author affiliations list:

J Haczynski ${ }^{1}$, Z Lew-Starowicz ${ }^{2}$, B Darewicz ${ }^{3}$, K Krajka ${ }^{4}$, R Piotrowicz ${ }^{5}$ and B Ciesielska ${ }^{6}$
${ }^{1}$ Eli Lilly Medical Department, Warsaw, Poland; ${ }^{2}$ Faculty of Rehabilitation Academy of Physical Education, Warsaw, Poland; ${ }^{3}$ Urology Clinic Medical Academy, Bialystok, Poland; ${ }^{4}$ Urology Clinic - Medical Academy, Gdansk, Poland; ${ }^{5}$ Clinic of Cardiology Rehabilitation - Institute of Cardiology, Warsaw, Poland and ${ }^{6}$ Specialty Psychiatry Outpatients Clinic Lodz, Poland 